чения респираторных мышц возможен летальный исход. Поэтому при тяжелых кризах показано применение аппаратного искусственного дыхания. Стандартное лечение миастении направлено на процесс иммунорегуляции и включает тимэктомию, применение кортикостероидов, иммуносупрессивных препаратов, что улучшает функциональный статус пациентов и уменьшает риск экзацербаций. Ряд современных исследований демонстрирует эффективное использование в купировании миастенических кризов высоких доз иммуноглобулинов внутривенно, что и предлагается в качестве альтернативного лечения острых экзацербаций заболевания. Однако показания к применению иммуноглобулинотерапии в длительном лечении миастении еще не установлены.

Франция, Service de Reanimation Medicale, Hopital Raymond-Poincare, Garches

\title{
M.Acierno
}

\section{ВЕРТИКАЛЬНАЯ ДИПЛОПИЯ}

\author{
(VERTICAL DIPLOPIA)
}

(Semin. Neurol. - 2000.-20(1).-21-30: Англ.)

A иагноз приобретенной вертикальной диплопии представляет некоторые трудности в силу отсутствия специфических диагностических тестов. Симптомы бинокулярной вертикальной диплопии могут появиться внезапно либо нарастать постепенно, в течение нескольких лет, причем некоторые пациенты даже не подозревают о наличии у них какихлибо отклонений. Основной дифференциальный диагноз вертикальной диплопии включает парез глазодвигательного нерва, паралич верхней косой мышцы, рестриктивные офтальмопатии и миастению. Дискутируются некото- рые другие этиологические факторы данного заболевания. Большинство клиницистов владеет диагностикой более часто встречающейся горизонтальной диплопии, поэтому уточнение клинической симптоматики вертикальной диплопии представляется важным для более правильного диагноза данной аномалии.

$C W I A$,
Department of Ophthalmology, University of Mississippi Medical Center, Jackson

\section{K.Ricker}

\section{РАСШИРЕННЫЙ КЛИНИЧЕСКИЙ И ГЕНЕТИЧЕСКИЙ СПЕКТР МИОТОНИЧЕСКИХ ДИСТРОФИЙ}

\author{
(THE EXPANDING CLINICAL AND GENETIC SPECTRUM \\ OF THE MYOTONIC DYSTROPHIES)
}

(Acta Neurol. Belg.- 2000. Sep.-100(3).-151-155: Англ.) рофии (болезнь Штейнерта) лежит генный дефект, расположенный в хромосоме 19 q13.3 (DM1 локус). Позже был описан еще один 
вариант заболевания, названный проксимальной миотонической миопатией (П ММ). У большинства семей с ПММ был обнаружен дефект в недавно открытом локусе DM2 хромосомы 3q21. Исследование посвящено клиническому анализу этого заболевания у 70 пациентов из 14 немецких семей. В отличие от болезни Штейнерта, ПММ у большинства пациентов имеет более доброкачественное течение. В клинической картине, как правило, не обнаруживается умственная отсталость; мышечная слабость наблюдается лишь в проксимальной мускулатуре нижних конечностей; миотонический синдром выражен слабо или отсутствует, нмеет место бо- левой синдром. Тем не менее при ПММ у части пациентов существует возможность серьезных сердечных осложнений и вероятность прогрессирования мышечной слабости. Авторами наблюдаются некоторые пациенты, имеющие фенотипические варианты ПММ, однако у них не обнаружены нарушения в хромосоме 3q21. Это дает основания полагать, что группа описанных типов миотони. ческих дистрофий может пополниться в будушем новыми вариантами заболевания.

Германия,

Department of Neurology, University of Wurzburg

\title{
D. Biondi
}

\section{ЦЕРВИКОГЕННАЯ ГОЛОВНАЯ БОЛЬ: МЕХАНИЗМ, КЛИНИКА И СТРАТЕГИЯ ЛЕЧЕНИЯ}

\author{
(CERVICOGENIC HEADACHE: MECHANISMS, EVALUATION \\ AND TREATMENT STRATEGIES)
}

(J. Am. Osteopath. Assoc.- 2000. Sep.-100(9 Suppl.).-S7-14: Англ.)

\section{II} ервикогенная головная боль - хронический гемикраниальный болевой синдром, развивающийся вследствие патологии шейного отдела позвоночника или мягких тканей шеи. Известно, что тригемино-цервикальное ядро - это регион в верхней части спинного мозга, где чувствительные нервные волокна нисходящего тракта тригеминального нерва конвергируют с чувствительными волокнами верхних шейных корешков. Посредством данной конвергенции ноцицептивных путей отраженные болевые сигналы от шеи достигают тригеминальных чувствительных рецептивных полей лица и головы, активируя тригемино-васкулярные нервные окончания. В свою очередь, существуют связи сенсомоторных волокон добавочного нерва и верхних спинальных корешков, которые также конвергируют с нисходящим трактом тригеминального нерва, что является бази- сом для передачи болевых импульсов с грудинно-ключично-сосцевидной и трапециевидной мышц в область лица и головы. Дифференциальная диагностика цервикогенной головной боли проводится с мигренью, головной болью напряжения и пароксизмальной гемикранией. Статья посвящена клинической характеристике цервикогенной гояовной боли, ее диагностическим критериям, патофизиологии и методам диагностической экспертизы. Предлагается программа лечения цервикогенной головной боли, включающая медикаментозную терапию, анестезиологические вмешательства, остеопатические манипуляционные процедуры и другие нефармакологические методы.

CIIIA,

Head Pain Division, Michigan Head-Pain \& Neurological Institute 